\title{
GLOBALIZAÇÃO E DIÁLOGO INTER-RELIGIOSO
}

\section{Pe. Fernando Altemeyer Junior}

No debate e diálogo inter-religioso intrigantes questões têm emergido. Face à crise da globalização temos sempre mais perguntas que respostas.

Diante do atual processo de globalização econômica podemos afirmar como o fez Martin Buber, em 1923, que toda vida real (verdadeira) é encontro (All real living is meeting)! no belo e atual "Ich und Du", ou ainda mais tarde no livro Diálogo, de 1930: "Uma época de genuínos colóquios religiosos está-se iniciando - não dos que assim se denominavam e eram fictícios. nos quais ninguém realmente olhava para seu parceiro e nem a ele se dirigia, mas uma época de diálogos genuínos, de certeza para certeza e também de uma pessoa receptiva para outra pessoa receptiva. Somente então aparecerá a comunidade autêntica, não aquela de um conteúdo de fé sempre autêntico, supostamente encontrado em todas as religiões, mas a comunidade da situação, da angústia e da expectativa"2. Ou a lógica da eficácia e do êxito, da forte competição capitalista teria sido internalizada pelas igrejas e religiões, reféns inconscientes do neoliberalismo gerando atitudes intolerantes, na denúncia recente feita em Lima pelo presidente do CLAI, pastor Dr. Walter Altmann. Quero mirar com humildade $o$ atual processo histórico com as categorias deste brilhante pensador judeu, Buber, para ancorar minha reflexão e abrir novos horizontes aos nossos corações.

\section{COMUNIDADE DE SITUAÇÃO}

Dialogamos por nos sentirmos situados e comprometidos com uma causa comum: a paz e a justiça social de nosso povo empobrecido. Nicolau de Cusa, em 1453, publica - livro De Pace Fidei, a paz pela fé, que é um verdadeiro manual para o encontro de religiões e culturas desenvolvendo o tema da concórdia universal. O livro deste místico cardeal alemão termina com a utopia de um concílio em Jerusalém para reconciliar todas as religiões.

Hoje, na bela expressão do Rabino Sobel: "judeus não buscam construir um mundo mais judaico mas sim um mundo mais humano". Faço

I Martin BUBER, I and Thou, Second Edition, Charles Scribner's Sons, New York, 1957, p. 11.

${ }^{2}$ Martin BUBER, Do diálogo e do dialógico, Ed. Perspectiva, São Paulo, 1982, p. 40. 
munhas suas palavras, em relação ao cristianismo libertador a partir de nossas comunidades católicas engajadas neste macro-ecumenismo e diálogo necessário. treito da competitividade se confronta com a necessária "re-invenção" da ética. O dramaturgo alemão Bertolt Brecht afirmara que o objetivo da ciência era o de aliviar a canseira humana - mas isto não é verdade nem na Europa nem na África e tampouco no Brasil às vésperas do $3^{\circ}$ milênio. Precisamos nos confrontar com questões candentes da conjuntura internacional: invisíveis do novo mercado global? $\mathrm{O}$ historiador crítico Eric Hobsbawn, em seu livro Era dos Extremos questiona: mia tecnocientífica são agora suficientemente grandes para destruir o meio ambiente, ou seja, as fundações materiais da vida humana. As próprias estruturas das sociedades humanas, incluindo mesmo algumas das fundações sociais da economia capitalista, estão na iminência de ser destruídas pela erosão do que herdamos do passado humano. Nosso mundo corre o risco de explosão e implosão. Tem de mudar"3.
O sistema neoliberal, no afã es-

1. Quais as fronteiras visíveis e

"As forças geradas pela econo-

2. Por que deveríamos incluir o diálogo como requisito indispensável deste processo de mundialização das informações e do capital?

Para salvar vidas de muitos e re conhecer que há um só senhor e Deus, o Eterno, vivo e verdadeiro e que sem comunhão e serviço teremos a multiplicação de ídolos e de injustiças que atentam contra a criatura e o Criador.

3. Devemos nos submeter ao "mercado" que produz tecnologia e simultaneamente exclusão em larga escala? Quem produzirá o sentido da vida e do viver? Quem determina o futuro do planeta?

Em Israel, o povo murmurou contra Moisés e contra o próprio Senhor, mas a experiência da sarça ardente fez um só homem de fé não sucumbir às cebolas e às mentiras do Faraó, e às multidões de corações transviados, mantendo a aliança.

O relato no livro do Exxodo capítulo 15, 22-27, que mostra este murmurar contra o profeta, termina com a poética cena da chegada a Elim, onde havia doze fontes de água e setenta palmeiras. Eis nosso horizonte utópico.

Recentemente outro homem de Deus, pastor luterano e mártir, Dietrich Bonhoeffer, em plena Alemanha Nazista, lutou contra a Shoah e contra a idolatria ariana, afirmando em suas cartas sua fidelidade ao único Deus que merece nossa entrega total:

"Quem sou eu? Seguidamente me dizem que saio da minha cela tão sereno, alegre e firme qual dono de um castelo....
${ }^{3}$ Eric HOBSBAWN, Era dos Extremos, Companhia das Letras, São Paulo, 1996, p. 562.
Quem sou eu? A própria pergunta nesta solidão, de mim parece pretender zombar. Quem quer que sempre eu seja, tu me conheces, oh, meu Deus, SOU TEU"4.

4. É possível produzir eticamente? A qualidade total e a norma ISO 9002 ou 14000 são os novos paradigmas de regulação do humano? Quem manda na produção? Qual é o sujeito do processo tecnológico? $E$ os atores sociais que interesses devem defender? E as religiões terão lugar neste mundo plena da imoralidade das guerras mantidas pelos fabricantes de armas e potências hegemônicas de todas as latitudes e coloridos ideológicos?

Hans Küng, teólogo católico de renome, afirma que uma nova ética mundial passa pela paz religiosa sem a qual não haverá paz mundial, e esta exigirá interpretações mais humanas de leis sacrais ultrapassadas e antihumanistas, fundadas na intolerância e na mentira ${ }^{5}$.

5. Para que dialogarmos? Como fim ou meio?

\section{COMUNIDADE DE ANGÚSTIAS}

Para viver a cidadania globalmente, precisamos vencer três obstáculos do discurso oficial das elites tecnocráticas:
1. Fatalismo diante do processo produtivo e do avanço tecnológico. Querem fazer crer que exclusão é inevitável è natural, como o rolar da pedra contínuo de Sísifo. Qualquer luta seria estéril. Procuram, inclusive, culpabilizar os pobres e miseráveis por sua miséria, gerando fatalismo e submissão. Buscar transformar as massas dos desempregados tecnológicos en Prometeus punidos por seres superiores. Ou aceitamos o processo ou estaríamos fatalmente destinados ao retrocesso.

2. A plenitude totalitária da mercadoria e a finitude do trabalho.

Numa compreensão neoliberal o que importa é a mercadoria e o ajuste monetário e, portanto, a imortalidade dos produtos e sua qualidade e não o ser humano e suas reais condições de saúde, educação e habilitação profissional. A mercadoria têm se subjetivado e o homem foi coisificado.

No tratado talmúdico Sanhedrin, um doutor sublinhava: "Salvar uma vida humana é como salvar o universo inteirinho, e destruir uma só vida é equivalente a destruir o próprio universo."

3. Situações de pecado na produção e economia globalizadas.

A questão da responsabilidade dos agentes econômicos e sociais, nos remete à questão das conseqüên-
4 Dietrich BONHOEFFER, Resistência e Submissão, Paz e Terra-Sinodal, Rio de Janeiro, 1980, $2^{\circ}$ Edição, p. 173-174.

5 Hans KÜNG, Proyecto de una ética mundial, Editorial Trotta, Madrid, 1992. 
cias morais na economia global. É urgente falarmos de pecado, omissão e negação nas relações humanas. A linguagem religiosa e ética de judeus e cristãos adquire atualidade e nexo como nunca antes.

Os meios devem ser adequados na construção de valores conscientes e nobres. Entre Sartre e Kant, sabemos que todo ato moral exige consciência e liberdade e deve gerar um hábito. É preciso superar o comportamento alienado que mantêm milhões de trabalhadores à margem das decisões e do usufruto dos produtos por eles mesmo construídos. Charles Darwin (1809-1882) já reclamava que "se a miséria de nossos pobres não é causada pelas leis da natureza, mas por nossas instituições, grande é a nossa culpa".

\section{COMUNIDADE DA EXPECTATIVA}

\section{Superar a escravidão}

A escravidão, a submissão (experiências bem brasileiras - escravidão hoje, prostituição infantil, preconceitos e dominação cultural, a prática da tortura) exigem um posicionamento claro e urgente de todos.

Em 1995 foram computados 26.047 pessoas em regime de escravidão no Brasil. $O$ índice, segundo a CPT, em 1994, era de 25.193 pessoas. Vale lembrar que a maioria são crianças. Se nem gente ainda o são imaginemos o quanto nos resta por fazer na conquista da cidadania.

\section{Fiscalizar o poder}

Regidos pela ética e não pelo lucro e pela competitividade, eis a questão da modernidade global. Como nos lembra Aristóteles, na Ética a Nicomaco"... tornamo-nos justos, praticando atos justos, moderados, agindo moderadamente, $\mathrm{e}$ corajosos, agindo corajosamente. Esta asserção é confirmada pelo que acontece nas cidades, pois os legisladores formam cidadãos, habituando-os a fazerem o bem". A cidadania guiada pela ética é a garantia dos direitos fundamentais dos trabalhadores e deve ser entendida como satisfação de necessidades fundamentais, de pão e de beleza, pois se "l'amore è un appetito di bellezza" (Lorenzo, o Magnífico) sabemos por Franklin D. Roosevelt que "homens necessitados não são homens livres".

\section{Defender a vida}

A cidadania, como exercício do consenso comunitário, exige uma nova pauta de ação das forças democráticas e da sociedade organizada. Assim pede o setor pastoral social da CNBB em seu livro Grito dos Excluídos: "Pensar um novo modelo de desenvolvimento econômico implica, concreta e verdadeiramente, no resgate do valor da pessoa humana, implica em construir uma nova sociedade, democrática, onde todos possam ser sujeitos atiyos e criativos na consolidação e gestão do cotidiano". Cidadania como construção de valores, já que mesmo Monstesquieu nos lembra que "a liberdade pode consistir somente em poder fazer aquilo que devemos querer".

A valorização do humano e sua primazia diante do capital e das tecnologias que excluam, submetam e danifiquem pessoas e meio-ambientes é tarefa necessária de todos os intelectuais e, também, da sociedade organizada.

O sociólogo Alain Touraine, no livro "O que é a Democracia", preocupa-se pois:

"Atualmente (a democracia) está mais inquieta porque a globalização esmaga a diversidade das culturas e experiências pessoais e porque o cidadão se transforma em consumidor."

\section{Mudar o local ecológico}

Processos produtivos e civilizatórios devem levar em conta a ecologia, o planeta e o equilíbrio entre as espécies. Biodiversidade e biocomplementariedade tornaram-se eixos de debate da nova engenharia humana, ou teremos a desertificação e a falta de bens essenciais por nos tornarmos predadores destrutivos.

\section{Diálogo religioso como um modo de ser}

a. Ouvir outras canções

Novos movimentos religiosos, fim de milênio, conflitos e guerras entre fundamentalistas, inculturação são rico cadinho de cultura a desafiar as mutheres e homens religiosos. Temos dificuldades em estabelecer um diálogo verdadeiro e profundo, isto é, a fazer viver a Verdade em nós e ter prazer em escutá-la nos outros. Este exercício interior e pessoal é difícil e pode durar toda uma vida, mas cremos que vale a pena.

Esta nova linguagem virá sempre acompanhada de novas atitudes diante da vida e do jeito de ser dos outros credos e crentes (e porque não dizer, diante dos não crentes, também!). Precisamos ouvir a canção e os murmúrios dos outros: "O primeiro idioma se aproximava mais do canto que da palavra"6. É com emoção que a humanidade e os outros irmãos cristãos ouviram o Papa João profetizar às vésperas do Concílio Ecumênico Vaticano II:

"Em qualquer parte onde os autênticos valores da arte e do pensamento são susceptíveis de enriquecer a família humana, a Igreja está pronta a favorecer este trabalho da inteligência. Ela mesma, vós o sabeis, não se identifica a nenhuma cultura, nem mesmo à cultura ocidental à qual no entanto sua história está estreitamente mesclada. Pois sua missão própria é de uma outra ordem: a da salvação religiosa do homem.

6 Paul CAZAYUS, L'aphasie du point de vue du psychologue, Dessart et Mardaga Editeurs, Bruxelles, 1977, p. 35 
Mas a Igreja, plena de uma juventude sem cessar renovada pelo sopro do Espírito, permanece disposta a reconhecer, a recolher, e mesmo a animar tudo o que honra a inteligência e o coração humano em outras praias do mundo que as desta Bacia Mediterrânea que foi o berço providencial do cristianismo"".

b. Reverência e respeito mútuo Somente venceremos a intolerância pelo respeito mútuo, ou nas belas palavras do Rabino Henry I. Sobel: pela reverência ao outro. Para chegarmos a uma reverência que supere a intolerância existe um fator objetivo que interfere em nossa atitude diante de outros fenômenos ou pessoas religiosas: é a liberdade de consciência, e certamente, a abertura à verdade do outro. Respeitar não significa aceitar viver sem a escuta. Quem respeita, ouve!

Precisamos quotidianamente assumir em nossas congregações ou comunidades religiosas o exercício da escuta e do respeito. A surdez em que nos metemos pode transformarse em fundamentalismo e ideologia. É óbvio que diálogo pressupõe a superação dos solilóquios e da descoberta do outro. Novas sínteses e abertura de posições pessoais são necessárias. Isto tem trazido dificuldades e colocado novos problemas pastorais, humanos e teológicos.

Isto é uma riqueza e um risco e dição e nossos pais na fé serão honrados e não relegados por convergiões. Descobrir a fé dos outros com amor e respeito é, inclusive, exigência evangélica:

"Uma correta apreciação de outras tradições religiosas pressupõe normalmente um contato estreito com estas. Isto implica, ao lado de conhecimentos teóricos, uma experiência real do diálogo inter-religioso com Entretanto, é também verdadeiro que uma avaliação teológica correta das tradições, ainda que em termos gerais, permaneça um pressuposto necessário para o diálogo inter-religioso. Estas tradições devem ser abordadas com grande respeito, em função dos valores espirituais e humanos que elas contêm. Elas requerem nossa consideração pois, através dos séculos, foram testemunhas dos esforços envidados para encontrar as respostas" aos enigmas escondidos da condição humana" (Nostra Aetate 1) e elas foram lugar de expressão da não nos deve intimidar. Nossa Trasamos com outros credos e relios adeptos destas mesmas tradições. experiencia religiosa e das mais pro-

${ }^{7}$ Cf. Discurso aos participantes do $2^{\circ}$ Congresso Mundial de escritores e artistas negros, in: "L'Osservatore Romano", 3 abril 1959, p. 1, citado na Encíclica Princeps negros, in: "L'Osservatore Romano JOÃO XXIII, datada de 28 de novembro de 1959 e publicada na Pastorum, Papa JOÃO XXIII, datada de 28 de jan-mars, Québec, Canadá, p. 119-120. fundas aspirações de milhões de seus membros: e, elas, ainda hoje, continuam a fazê-lo e a ser"s.

Eis a reflexão do mestre e filósofo francês Paul Ricoeur, falando sobre a questão da verdade, apresentada numa cerimônia em que the foi concedido o título de Doutor Honoris Causa:

"Em primeiro lugar devemos renunciar a uma relação possessiva da verdade; não devemos dizer: eu tenho a verdade, mas sim, eu espero estar na verdade. A pior maneira de encontrar o outro é de anular sua intenção de verdade, tanto quanto a minha. Todo diálogo desaparece quando não há confrontação, onde não existe mais convicção" 9 .

c. Novos tempos e novas pessoas

Vivemos novos tempos e precisamos de novas pessoas ${ }^{10}$. O diálogo torna-se uma realidade teológica viável e prática pois cristãos e outros irmãos religiosos vivem expericonvivência e partilha. Precisamos da missão" .

$O$ verdadeiro diálogo não se camufla na areia movediça da neutralinestidade sincera de parceiros diferentes. Não é uma fotocópia nem troca de gentilezas ou diplomacia de elites religiosas. De certa forma é um novo jeito de falar de Deus:

"O diálogo é antes de tudo um estilo de ação, uma atitude e um espírito que inspira o comportamento. Uma missão que não fosse impregnada do espírito do diálogo seria contrária às exigências da natureza humana e aos ensinamentos do Evangelho"'2. ências transparentes e honestas de crítica dos outros e não de sua subdade. O diálogo é argumento e ho-

${ }^{8}$ Pontifício Conselho pró diálogo inter-religioso, Documento: Diálogo e anúncio: Dois aspectos da missão evangelizadora da Igreja, parágrafo $n^{\circ} 14$, in Bulletin, (78)1991aspectos da missão evangelizador
XXVI/3, Vaticano, 1991, p. 266.

${ }^{9}$ Paul RICOEUR, De l'esprit, in Fête patronale du 2 février 1994, Bulletin Louvain, mars 94/46, Louvain-la-Neuve, 1994, p. 29.

10 "Nós somos os herdeiros do Vaticano II. O Concílio transformou irreversivelmente o modo segundo o qual nós nos vemos uns aos outros." CNBB- Conferência Nacional dos Bispos do Brasil, Guia para o diálogo católico-judaico no Brasil, in: Estudos da $C N B B$ n $^{\circ} 46$, Paulinas, São Paulo, 1986, p. 9.

11 "O diálogo é sobretudo uma necessidade teológica na nova experiência brasileira. Se a preocupação fundamental é a vida do Reino de Deus sobre a terra brasileira, o encontro com as outras religiões é indispensável. A Igreja Católica no Brasil já avançou no diálogo com o judaísmo. As relações com as outras religiões presentes no Brasil estão ainda nos primeiros passos." CNBB: Conferência Nacional dos Bispos do Brasil, Guia para o diálogo inter-religioso, in: Estudos da $C N B B \mathrm{n}^{\circ}$ 52, Edições Paulinas, São Paulo, 1987, p. 25.

12 Pont. Conselho pró-Diálogo inter-religioso, Atitude da Igreja católica diante dos crentes de outras religiões (Reflexões e orientações concernentes ao diálogo e a missão), in: Bulletin, 56 (1984) XIX/2, , Vaticano, 1984, p. 156-157. 
Desrespeitamos a Deus quando desrespeitamos ou menosprezamos a fé alheia e diferente da nossa.

Ao amar nosso Deus precisamos amar o outro, o diferente em sua diferença. Estamos somente no limiar do conhecimento se cada dia não recomeçarmos e ampliarmos visões, amores e olhares. O reconhecimento mútuo exige muito trabalho, orações e empenho pessoal. Deve ser compromisso de vida, como canta o poeta argentino Atahualpa Yupanki:

"Qué lindo destino el mío si lluvia pudiera ser! Besar la tierra sedienta y entre las piedras correr!
La lluvia tiene un destino que yo quisiera tener. El sol la lleva a los cielos para ser lluvia otra vez."

É sobretudo obra do Espírito de Deus: "Colocarei minha lei em seu peito e a escreverei em seu coração; eu serei o Deus deles e eles serão o meu povo." (livro do profeta Jeremias $31,33)$

Pe. Fernando Altemeyer Junior pertence ao Vicariato da Comunicação da Arquidiocese de São Paulo.

Av. Higienópolis, 890, 01238-908 - São Paulo - SP.

\title{
A ORAÇÃO DE DAVI: UMA ANÁLISE SÓCIO. POLÍTICA CONTEXTUALIZADA NOS FATOS HISTÓRICOS
}

\author{
Jeni Bertoni Nimtz
}

A Confederação Israelita, consolidada por uma organização tribal de duzentos anos de existência, sofreu, em finais do século XI a.C. uma violenta agressão por parte dos filisteus. Tal conflito, que se estendeu por quase todo o período dos Juízes, intermitente e intenso, acabou levando Israel à ruína total, sem a mínima esperança de se reerguer... Haveria de desencadear-se, porém, uma série de acontecimentos significativos, capazes de estabelecer a unicidade de todo o povo, restaurar o seu valor histórico para que, em menos de um século, a região se tornasse uma das maiores potências de sua época.

Fontes extremamente ricas encontram-se na literatura deuteronomística, existente nos seguintes blocos: $1 \mathrm{Sm}$ e $2 \mathrm{Sm}, 1 \mathrm{Rs}, 1,11$.

$\mathrm{O}$ advento da monarquia sob a liderança carismática de Samuel (o último da antiga ordem dos Juízes), consagrado a Iahweh antes do nascimento com um voto feito no santuário diante do sacerdote Eli, tornava-se um golpe indispensável, decisivo, para expulsar o invasor da Terra. Saul, o primeiro de uma série de monarcas foi ungido, privadamente, por Samuel, em Ramá (1Sm 9, 1 a
10, 16) sob aclamação do povo que se opunha à contrariedade do próprio Samuel.

A continuidade da ameaça dos filisteus, aliada aos acessos de depressão que acometera Saul durante seu curto reinado - provavelmente uma década antes de 1000 anos a.C. ("Um espírito maligno enviado por Deus"- 1Sm 16,14-23), o rompimento com Samuel, os seqüentes atos de crime, perseguição e impiedade desferidos contra um jovem servo, hábil músico, valente guerreiro que crescia carismaticamente a seu lado, foram as principais causas da decadência inevitável de sua presença como Rei. A conseqüente ascensão de Davi ao trono, a conquista de Jerusalém, a vitória sobre os filisteus, o transporte da Arca de Deus para o alto da colina ( $2 \mathrm{Sm} 5$; 2Sm 6) e a excelência da profecia de Natã (2Sm 7) são os acontecimentos que introduzem a Oração de Davi, (objeto deste estudo), seguidos pelas guerras empreendidas por ele, sujeitando filisteus, moabitas e arameus ao seu jugo e, finalmente, fazendo justiça a todo o povo.

As características da literatura específica do bloco deuteronômico (Juízes, Reis, Samuel e Josias), ca- 